\title{
EDUCAÇÃO EM SAÚDE PARA ALUNOS DE PRIMEIRO GRAU. AVALIAÇÃO DE MATERIAL PARA ENSINO E PROFILAXIA DA ESQUISTOSSOMOSE*
}

\author{
Virginia T. Schall** \\ Pedro Jurberg** \\ Elizabeth M. Almeida*** \\ Clarice Casz*** \\ Fátima G. Cavalcante*** \\ Silvana Bagno***
}

\begin{abstract}
SCHALL, V. T. et al. Educação em saúde para alunos de primeiro grau. Avaliação de material para ensino e profilaxia da esquistossomose. Rev. Saúde públ., S. Paulo, 21:387-404, 1987

RESUMO: Considerando a importância da informação sobre a esquistossomose para alunos de 7 a 15 anos, faixa etária apontada como de alta prevalência em regiōes endêmicas e cujos hábitos colaboram para a disseminação da doença, foi elaborado um material de ensino baseado em um texto de conotaçấo literária, o qual foi aplicado em escolas de região considerada foco isolado da doença no Município do Rio de Janeiro (Brasil). Desenvolveu-se uma metodologia de uso do material a ser empregada pelos professores, que resultou eficaz em promover aprendizagem de conceitos e cuidados básicos em relação à esquistossomose. Propõe-se o uso deste processo para outras doenças parasitárias a serem testadas em áreas caracteristicamente endêmicas.
\end{abstract}

UNITERMOS: Educação em saúde, métodos. Saúde escolar. Esquistossomose, prevenção e controle. Materiais de ensino.

\section{INTRODUÇÃO}

Sendo a esquistossomose uma endemia que vem se expandindo no Braisl nos últimos anos, torna-se necessário, em paralelo às pesquisas a ela voltadas, estabelecer medidas sanitárias, médicas e educativas que possam auxiliar seu controle.

Estudos sobre essa doença, no Brasil, têm mostrado sua alta prevalência na faixa de 6 a 20 anos de idade (Pellon e Teixeira ${ }^{31}$, 1953; Cotta e Andrade ${ }^{10}, 1967$; Paulini e col. ${ }^{30}, 1967$; Vinha $^{44}$, 1968; Castro-Filho e Silveira ${ }^{6}$, 1979; Coura e col. $\left..^{12}, 1983\right)$ o que também ocorre em outros países, como no Egito (Farooq e Samaan $^{16}$, 1967), na Etiópia (Polderman ${ }^{35}$, 1974) e na Nigéria (Ejezie e Ade-Serrano ${ }^{15}$, 1981), dentre outros. Tal é a importância do segmento infanto-juvenil da população, que a faixa etária de 7 a 14 anos foi adotada como parâmetro operacional para as atividades de controle, onde a prevalência é investigada pela SUCAM (Superintendência de Campanhas em Saúde Pública) em nosso país (Castro-Filho e Silveira ${ }^{6}, 1979$ ).

Esta alta prevalência está ligada ao contato com a água que, em geral, é maior entre crianças e jovens. Deve-se considerar que, nessa faixa etária, não estão bem consolidados os hábitos de higiene e é grande a frequiência a rios, lagoas, etc., principalmente em áreas menos desenvolvidas, onde são poucas as opções de lazer. Estes fatores contribuem para a aquisição da doença, como mostram os estudos de índices de transmissão da esquistossomose em crianças de 10 anos ou menos (Pessoa e Amorim $^{34}, 1957$; Persigan e col..$^{33}$, 1958; Conceição e Coura ${ }^{7}$, 1978; Meneses e Coura ${ }^{26}, 1979$ ).

* Trabalho elaborado com auxílio financeiro do Conselho Nacional de Desenvolvimento Científico e Tecnológico (CNPq — Proc. 30.0074/81, 10.0225/84 e PIDE VI) e da Coordenação de Aperfeiçoamento de Pessoal de Nível Superior - CAPES (PADCT/CAPES-PI 246/85).

** Apresentado na XXXVI Reuniăo Anual da Sociedade Brasileira para o Progresso da Ciência SBPC, São Paulo, 1984.

*** Departamento de Biologia do Instituto Oswaldo Cruz. Caixa Postal 926 - 21040 - Rio de Janeiro, RJ - Brasil.

**** Laboratório de Comportamento Humano e Animal do Instituto de Psicologia da Universidade do Estado do Rio de Janeiro - 20000 - Rio de Janeiro, RJ - Brasil. 
Além disso, os portadores de esquistossomose nesta faixa etária são grandes eliminadores de ovos do Schistosoma mansoni, muitas vezes sobrepondo as taxas de adultos $\left(\operatorname{Rey}^{38}, 1956\right.$; Katz e col. ${ }^{19,20}, 1978,1980$ e Costa e col. ${ }^{9}$, 1980). Desta forma, tanto os hábitos quanto a fisiologia contribuem para que as crianças participem ativamente na manutenção do ciclo de transmissão da doença. Castro-Filho e Silveira $^{6}$ (1979) mostraram que no tratamento coletivo de uma população, $80 \%$ dos casos persistentes são de menores de 14 anos e, nessa faixa, constata-se que, dos $90 \%$ de cura 45 dias após a medicação, ocorre um decréscimo para $40 \%, 365$ dias depois.

Considerando que um grande número de crianças e jovens frequienta hoje alguma escola de primeiro grau, ressalta-se a ausência de informação sistemática adequada sobre a doença nas séries de primeira a quinta. Esta evidência foi observada ao se analisar o documento: "Apoio a Elaboração do Currículo Pleno - Bases para o ensino de primeiro grau Ciências, 1980"*. Embora o programa contetha em sua introdução a afirmativa de que a "Saúde e a Ecologia" sejam as "linhas mestras de trabalho", verificou-se que a subárea denominada "Defesa da Saúde" representa apenas $11 \%$ dos itens gerais de Ciências. Apenas na $6 .^{a}$ série é incluído o ensino de doenças parasitárias, não se levando em conta que faixas etárias menores ( 7 a 12 anos) estão vulneráveis à aquisição de tais moléstias, porque além de estarem sujeitos a condições socioeconômicas precárias, faltam-lhes informações adequadas. Além disso, não se registra nenhuma atenção específica para o ensino sobre doenças que são endêmicas na circunvizinhança de certas escolas. Isto foi comprovado em entrevistas com professores de primeira a quarta séries do primeiro grau de escolas situadas em áreas consideradas focos isolados da esquistossomose no Rio de Janeiro, como o Alto da Boa Vista e Jacarepaguá. Muitos dos professores não possuíam conhecimentos básicos sobre a doença e desconheciam a sua prevalência naquelas áreas.

Outro fato observado está na carência de materiais didáticos específicos sobre a doença, que possam dinamizar e motivar o ensino, gerando maior interesse e participação dos alunos.

Quanto à esquistossomose, a educação sanitária se justifica, em paralelo às demais medidas (controle dos vetores e trematódeos, sa- neamento, tratamento médico da população infectada, entre outras...), pois como se tem enfatizado, esta doença não se deve apenas à permanência dos caramujos e pessoas doentes, mas aos hábitos, costumes e tradições das populações que favorecem sua disseminação através da poluição fecal do solo e das águas usadas para diversos fins, como banho, lavagem de roupa, lazer, pesca, etc. Salienta-se ainda o fato de a doença provocar sintomas toleráveis pelo indivíduo e não representar ameaça fatal de morte a curto prazo, o que não gera, no mesmo, atitudes de evitá-la. Green ${ }^{17}$ (1982) aponta 3 fatores que influenciam o comportamento relativo à saúde por intervenção educacional como: fatores de predisposição (conhecimentos, atitudes, opiniōes, crenças e percepções, cabendo à educação apontar as inconstâncias nos valores e erros na percepção da realidade); fatores de capacitação (habilidades e outros recursos requeridos pelo aprendiz para levar adiante a ação, quando motivado); fatores de reforçamento (recompensas sociais advindas da mudança comportamental).

Neste sentido, desenvolveu-se um material educativo que atingisse os fatores de predisposição, o qual foi testado quanto à sua eficiência em provocar mudanças conceituais, esclarecendo sobre atitudes incorretas e apontando alternativas preventivas. O material educativo desenvolvido visa oferecer às crianças noções básicas sobre esquistossomose como: - papel das fezes na contaminação do solo e das águas; - que a doença é adquirida em ambientes aquáticos onde exista o caramujo hospedeiro; - que esta limita a capacidade de aprender e trabalhar; - que tem cura, mas pode ser readquirida através de novos contatos; - reforçar comportamentos alternativos para evitar a doença, incentivando a divulgação do conhecimento à comunidade $e$ participação em medidas profiláticas.

O exemplo de asseio ambiental como, usar locais distantes das águas e cobrir as fezes quando eliminadas em ambiente natural, ao invés de sugerir sair em busca de um banheiro, no caso da criança que brinca longe de casa, é uma forma de oferecer uma alternativa que não cause conflito em relação aos padrōes de comportamento já estabelecidos, como recomenda Knutson ${ }^{21}$ (1953). Como apontam Coutinho e Pimont ${ }^{13}$ (1981), o fracasso na educação sanitária deve-se à "inoperância do conhecimento adquirido em termos de modificação

* Documento elaborado pela Secretaria de Educação da Prefeitura da Cidade do Rio de Janeiro, RJ. Dados inéditos. 
de práticas de vida muito antigas e sedimentadas, como as que implicam em riscos de contaminação (banho de rio, pesca, etc. .)". A "mensagem" neste caso, parecerá "sem uso" porque os indivíduos não têm alternativas substitutas para os seus hábitos.

Além do conteúdo da mensagem transmitida pelo material, procurou-se testar a sua adequação à faixa etária a que se destina, quanto à linguagem e ilustrações, atendendo ao que define Oliveira ${ }^{28}$ (1979) sobre os materiais ou meios instrucionais, que devem ser "instrumentos físicos que possibilitem a transmissão de estímulos necessários à aprendizagem, visando reforçar orientações e facilitar o processo ensino/aprendizagem". Portanto, sua adequação tem suma importância para que se alcance as metas ou objetivos pretendidos.

Objetivou-se, portanto, neste trabalho, medir a eficácia do material quanto ao seu papel de motivar a criança, mobilizando a sua atenção sobre o assunto focalizado, de transmitir corretamente as informações através de uma linguagem acessível à compreensão infantil e de permitir uma assimilação mais duradoura dos novos conhecimentos através de atividades extra-curriculares. Para tal, foi utilizada a técnica de observação de comportamento dos alunos da amostra submetida ao teste, atividades e exercícios para verificar a adequação da linguagem, medir a compreensão e a aprendizagem.

\section{MATERIAL E MÉTODOS}

\section{Local de Estudo e Amostra}

O projeto foi executado no Alto da Boa Vista, área considerada foco isolado da esquistossomose na cidade do Rio de Janeiro (Coura e col. ${ }^{11}, 1970$; Paes e col. ${ }^{29}$, 1970; Schall e col. $\left.{ }^{41}, 1985\right)$, em três escolas da Rede Municipal de Ensino. As escolas testadas, designadas como JSA, MM e MV, estão situadas nas imediações de riachos e hortas irrigadas, onde são encontrados caramujos da espécie Biomphalaria tenagophila (Mapa detalhado da região em Schall e col..$^{41}$, 1985).

O material foi testado em uma amostra de 231 escolares, de $3 .^{\mathrm{a}}$ a $5 .^{\mathrm{a}}$ séries do primeiro grau (Tabela 1), sendo quatro turmas de $3 .^{\mathrm{a}}$ série, três de $4 .^{a}$ e duas de $5 .^{\mathrm{a}}$. A faixa etária variou de 8 a 15 anos, supondo-se adequada ao tipo de texto aplicado.

Nas Escolas JSA e MV a amostra foi subdividida em dois grupos, sendo 3 classes submetidas ao material de controle e 3 (equivaIentes quanto à série e características gerais dos alunos, como aproveitamento acadêmico, classe socioeconômica, idade e local de moradia, como condições de padronização das variáveis da amostra) submetidas ao material experimental. Nas 3 classes da Escola MM foi testado apenas o material experimental.

Participaram da pesquisa 8 professores, cujo comportamento foi observado durante a aplicação dos materiais em sala de aula, para que se pudesse avaliar características como: forma de aplicação, conhecimento demonstrado, recursos didáticos, motivação, controle de turma, observações estas que poderiam influir nos resultados, atuando como variáveis intervenientes no processo.

\section{Material}

Foram utilizados os seguintes materiais:

a. Uma ficha de entrevista, para obtenção de dados da amostra de escolares referentes à situação socioeconômica, características da habitação, conceito de saúde, hábitos de higiene e conhecimento prévio sobre a esquistossomose.

b. Um texto infantil denominado "O Feitiço da Lagoa"*, escrito por Schall ${ }^{40}$, 1982, ilustrado por J. R. Mac Cord, foi

TABELA 1

Distribuição da amostra estudada por escola e por entrevista

\begin{tabular}{|c|c|c|c|c|c|c|c|c|}
\hline \multirow{4}{*}{ Escolas } & \multirow{4}{*}{$\begin{array}{l}\text { N. }{ }^{\circ} \text { de } \\
\text { turmas }\end{array}$} & \multirow{4}{*}{$\begin{array}{l}\text { N. }{ }^{\circ} \text { de } \\
\text { alunos }\end{array}$} & \multicolumn{6}{|c|}{ N..$^{\circ}$ de alunos entrevistados } \\
\hline & & & \multicolumn{4}{|c|}{ Grupo I } & \multirow{2}{*}{\multicolumn{2}{|c|}{$\frac{\text { Grupo II }}{\begin{array}{c}\text { Entrevista } \\
\text { posterior }\end{array}}$}} \\
\hline & & & \multicolumn{2}{|c|}{$\begin{array}{c}\text { Entrevista } \\
\text { anterior }\end{array}$} & \multicolumn{2}{|c|}{$\begin{array}{c}\text { Entrevista } \\
\text { posterior }\end{array}$} & & \\
\hline & & & $\mathrm{n}$ & $\%$ & $\mathrm{n}$ & $\%$ & $\mathrm{n}$ & $\%$ \\
\hline $\begin{array}{l}\text { JSA } \\
\text { MM } \\
\text { MV }\end{array}$ & $\begin{array}{l}4 \\
3 \\
2\end{array}$ & $\begin{array}{l}95 \\
76 \\
60\end{array}$ & $\begin{array}{l}33 \\
26 \\
20\end{array}$ & $\begin{array}{l}34,7 \\
34,2 \\
33,3\end{array}$ & $\begin{array}{l}28 \\
24 \\
18\end{array}$ & $\begin{array}{l}29,4 \\
31,6 \\
30,0\end{array}$ & $\begin{array}{l}31 \\
23 \\
18\end{array}$ & $\begin{array}{l}32,6 \\
30,3 \\
30,0\end{array}$ \\
\hline Total & 9 & 60 & 79 & 34,2 & 70 & 30,3 & 72 & 31,2 \\
\hline
\end{tabular}


utilizado como material experimental. $O$ texto em verso (do tipo cordel) conta a história de um menino sadio que adquire a esquistossomose ao entrar em uma lagoa a convite de amigos, o que provoca mudanças em sua vida. Levado ao médico, esclarecido sobre a doença (que pensa ser um feitiço) e curado, retorna à escola, transmite os conhecimentos e propõe divulgação na cidade e reivindicação de melhoria nas condições da lagoa (Fig. 1).

c. Folheto instrutivo sobre a esquistossomose da SUCAM (Fig. 2a-b), foi utililizado como material de controle.

d. Materiais adicionais: - Folha padrão com reprodução reduzida das ilustrações da história, para avaliar a retenção do enredo, nas turmas experimentais; - Suplemento de trabalho - (série diversificada de exercícios do tipo completar palavras cruzadas e outros, para avaliação da aprendizagem nas turmas experimentais e controle); - Modelo do caramujo transmissor da doença para recortar e montar por colagem; - Ilustrações do texto ampliadas, afixadas em cartolina, para uso do professor ao apresentar a história; - Folheto de instrução sobre método de aplicação para os professores das turmas experimentais e de controle.

e. Material para exame de fezes da amostra: frascos plásticos para coleta de fezes e fichas de resultado do exame.

\section{Procedimentos}

O plano geral de pesquisa baseou-se no modelo de Solomon (Matheson e col. ${ }^{25}, 1970$ Tabela 2) adequado aos estudos nos quais é necessário obter uma medida anterior (pré-teste) ao tratamento experimental, o que pode funcionar como uma variável independente em si e alterar os resultados, já que os alunos entrevistados anteriormente podem ficar mais atentos às aulas sobre $o$ assunto $e$ apresentarem melhor rendimento. Desta forma, dois terços da amostra (sorteados aleatoriamente) foram subdivididos em 4 grupos, sendo 2 de controle e 2 experimentais e dentre estes, apenas um submetido a entrevista anterior (pré-teste) e todos os 4 à entrevista posterior (pós-teste). Tanto os alunos do grupo de controle quanto os do grupo experimental provinham das mesmas séries, e com características gerais semelhantes (faixa etária, classe social, rendimento escolar, bairro de origem). Portanto, a amostragem foi por emparelhamento no primeiro estágio. No segundo estágio, para escolher os alunos a serem entrevistados, utilizou-se de uma amostragem aleatória simples, através de sorteio por computador.

Seguindo tal orientação, o trabalho foi realizado em três etapas, sendo:

1. ${ }^{a}$ etapa: Aplicação da entrevista anterior em um terço da amostra (Grupo I), totalizando 79 escolares, escolhidos por uma tabela de números aleatórios, após listagem de todos os indivíduos das turmas experimentais e de controle.

Os entrevistadores foram previamente treinados para homogeneizar a maneira de se proceder a entrevista, que foi realizada oral e individualmente. A entrevista constou de 22 questões relacionadas à habitação, estrutura familiar, atividades extra-escolares, conceito de saúde, cuidados em relação à saúde, reconhecimento do caramujo hospedeiro e conhecimento sobre a esquistossomose. As questões sobre habitação foram feitas após solicitação do desenho da própria casa do aluno. Diante do desenho, o entrevistador solicitava que o aluno indicasse os cômodos (número e tipo, por exemplo: uma sala, dois quartos, etc.). Por último perguntava-se pelo banheiro, se era dentro ou fora de casa ou se não havia. Sobre as atividades extra-escolares era investigado o tipo de atividade que o aluno fazia fora do horário da escola, como trabalhos ou brincadeiras. Quanto à saúde foram feitas três questões: 1) o que é saúde para você, 2) como mantém ou cuida de sua saúde, 3) o que faz para evitar adoecer. Também foi perguntado sobre o hábito de tomar banho ou nadar em águas de ambientes naturais e quais os motivos para tal. Para o reconhecimento do caramujo hospedeiro, eram apresentados ao aluno dois exemplares de Biomphalaria tenagoghila (o hospedeiro intermediário da esquistossomose na região) em uma placa de petri com algodão umidecido. Diante do animal, perguntava-se ao aluno se já o havia visto, em que locais, se ele podia causar algum mal e que tipo de doenças. Sobre a esquistossomose, perguntava-se: "Você sabe o que é esquistossomose?" Além das questões, o entrevistador

* O texto "O Feitiço da Lagoa" já está publicado pela Edições Antares, Rio de Janeiro, 1986, integrando a coleção "Ciranda da Saúde", financiada pelo PADCT/CAPES - Subprograma Educação para a Ciência. 


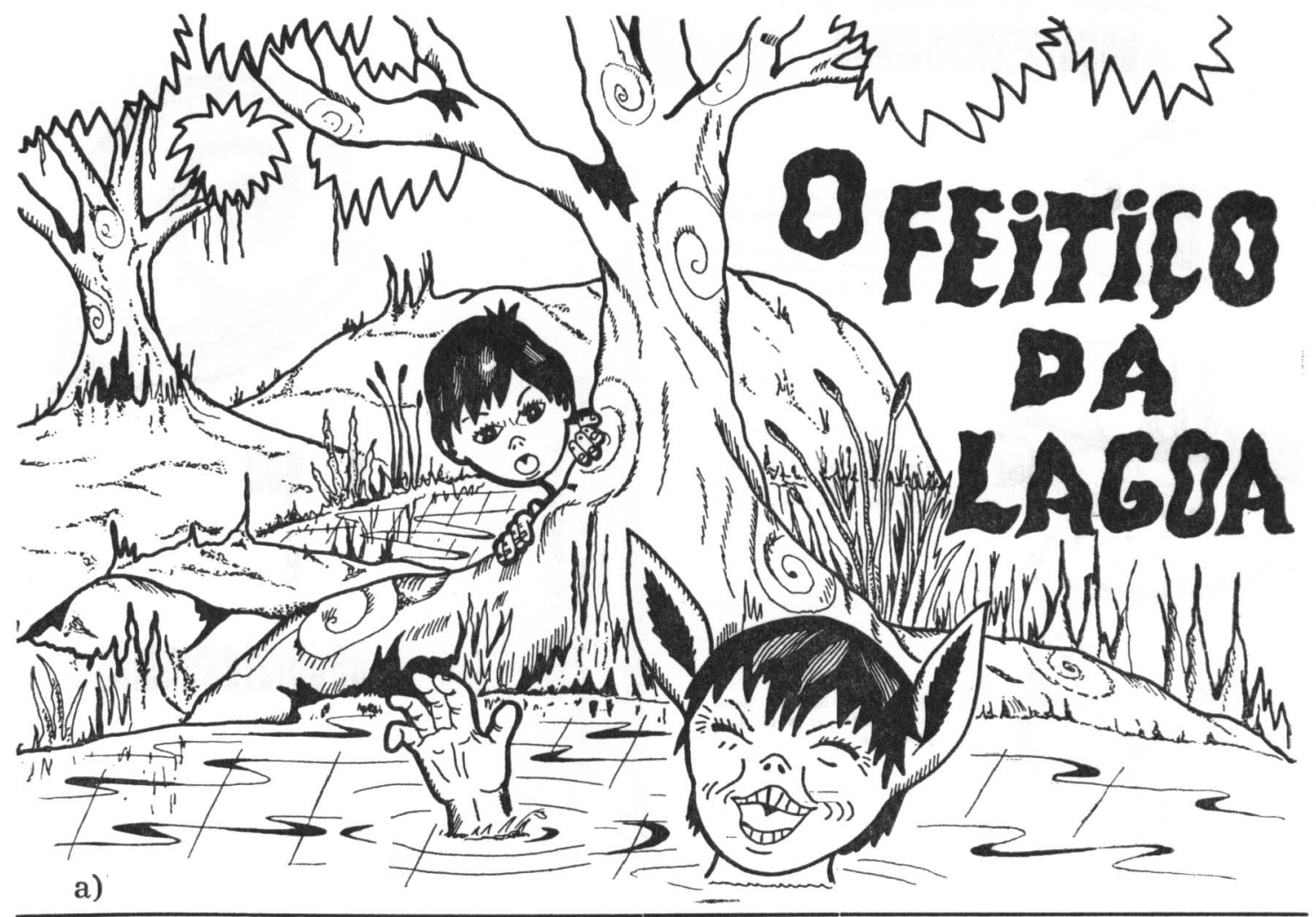

a)

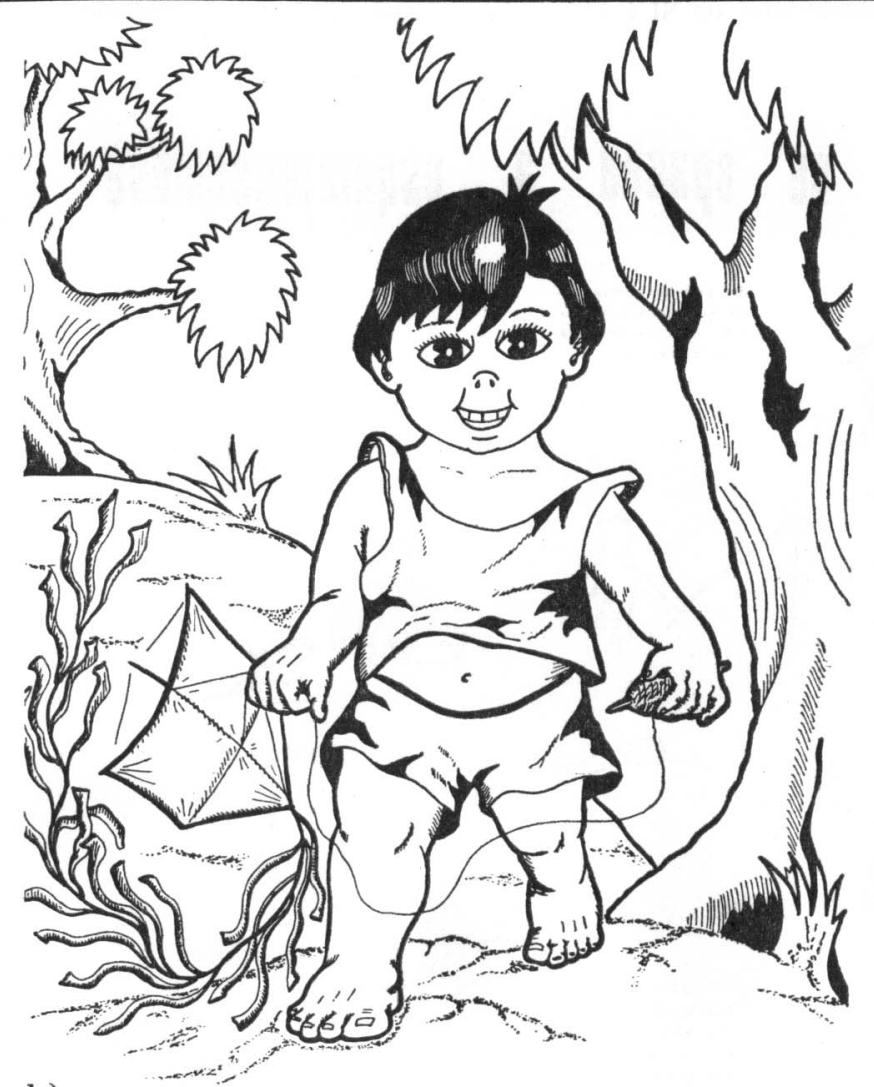

Se havia um menino sapeca,

esperto, levado da breca,

este era o Maneco.

Maneco sabe-tudo.

Maneco moleque e comilão,

cheio de animação.

E era tão engraçadol

Sabia fazer piada,

até quando as coisas

não,estavam lá muito boas nada.

Além do velho boné

sobre a cabeça chata,

em sua cara de bolacha,

o risco largo do sorriso

atravessava.

E se ficasse quieto

ah, só podia ao certo

estar fazendo das suasl

Não dava folga ao estômago

$\boldsymbol{e}$ as bochechas vermelhas

nunca tinham descanso.

nem os quintais da vizinhança.

Banana, laranja, goiaba,

jatobá, ingá, fruta-de-conde,

era uma comilança.

E tanto corria, e tantas fazia,

que sua mãe não sabia

onde o filho arranjava

tanta energial

b)

Fig. 1 (a) Capa e (b) página central da história infantil "O Feitiço da Lagoa"40 sobre esquistossomose, utilizada como material experimental. 


\section{EDIno Eambater a Bfquistiossomose}

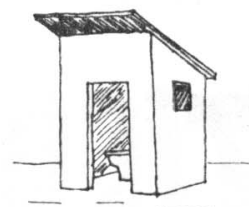

Use sempre a privada e faç com que sua familia use também.

Assim impedirá que as tezes se espalhem, contaminando solo e as águas.

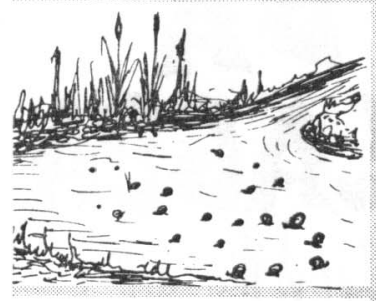

Cuidado com as águas que tềm caramujo. roupa e năo deixe que as crinessas águas.

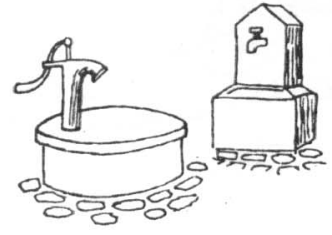

Use sobmente água de chafa riz, cacimba ou poço bem protegidos.

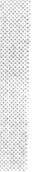

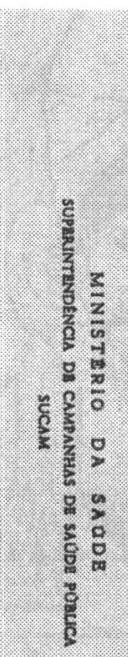
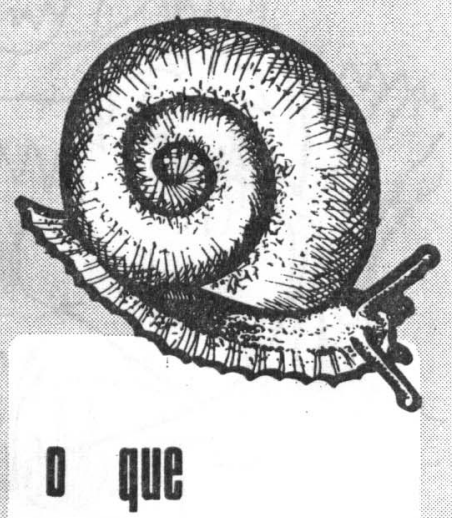

1

egquistossomase

Fig. 2a - Folheto ilustrativo sobre esquistossomose da SUCAM, utilizado como material de controle (frente).

\section{egquistossomose}
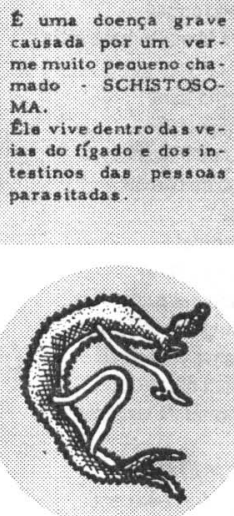

Ouem tem ente verron está sujeito a diarré ins, disenterias ob prisà̃o de ventre.

Os doentes de esquis: tossomose na lase mais grave tem o ba: ģo o o rigato multo au mentadou podendo apresentar barriga dó gua.

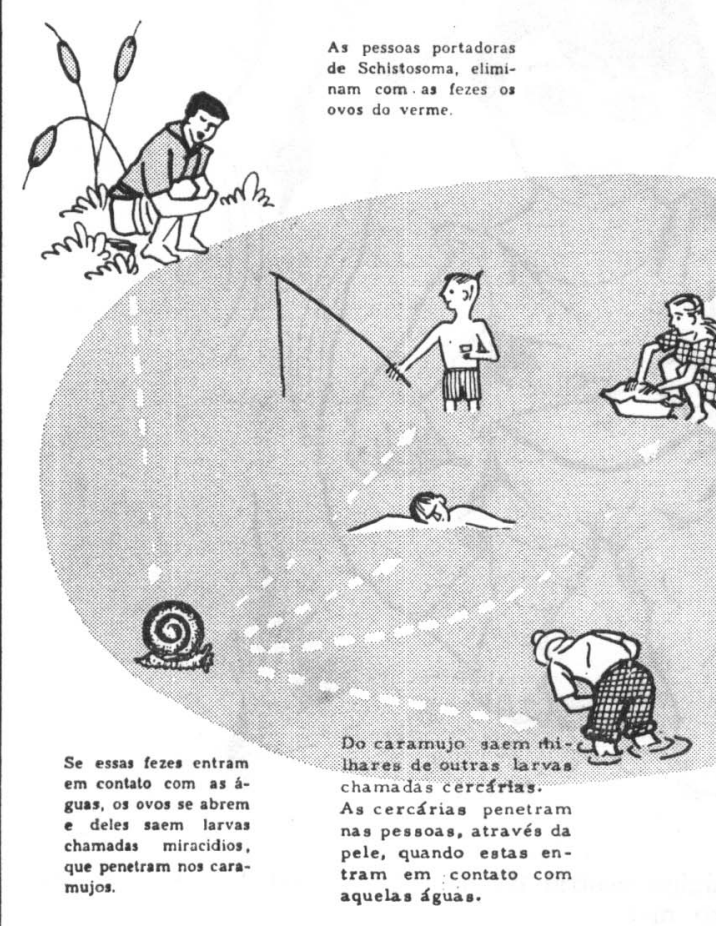

As cercórias que penetram nas pessons, v⿺辶。 mar dentro das veias do tigado em verme adulto - o Schis. tosoma.

Fig. 2b - Verso do folheto ilustrativo sobre esquistossomose da SUCAM, utilizado como material de controle. 
TABELA 2

Modelo do plano de pesquisa (Modelo Solomon)*

\begin{tabular}{lcccc}
\hline Situação & Grupos & $\begin{array}{c}\text { Entrevista } \\
\text { anterior }\end{array}$ & Tratamento & $\begin{array}{c}\text { Entrevista } \\
\text { posterior }\end{array}$ \\
\hline Experimental & I & Xa & Y1 & Xb1 \\
& II & & Y1 & Xb2 \\
\hline Controle & III & Xa & Y2 & Xb3 \\
& IV & & Y2 & Xb4 \\
\hline
\end{tabular}

Ver Matheson e col.25 (1970).

registrava observações sobre a aparência, limpeza e desembaraço do aluno.

A entrevista era iniciada por um "rapport" para amenizar atitudes de timidez ou inibição do aluno. Depois, procedia-se às questões, anotando-se as respostas em uma folha de ofício dividida verticalmente ao meio. As respostas eram anotadas do lado esquerdo do papel. Do lado direito eram registradas as perguntas feitas pelos alunos e a resposta dada pelo entrevistador, para avaliar as possíveis variações no padrão de entrevista estabelecido ou necessidade de mudança da estrutura de alguma questão.

Nesta etapa também foi realizado o levantamento croposcópico de toda a amostra, para avaliar a prevalência da esquistossomose e de outras parasitoses intestinais nesses escolares, cujos resultados foram descritos por Schall e $\mathrm{col}^{41}$ (1985). Os escolares positivos foram encaminhados ao Posto de Saúde do local, para tratamento.

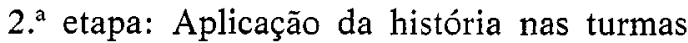
experimentais e do folheto da SUCAM nas turmas de controle: Toda a amostra foi submetida a um dos tratamentos (experimentais ou controle).

$\mathrm{Na}$ Escola JSA os professores aplicaram os materiais segundo métodos próprios. O método que resultou mais eficaz na turma experimental foi recomendado aos professores da Escola MM, onde só se aplicou a história.

Na Escola MV, o mesmo professor aplicou o tratamento experimental para uma turma $e$ controle para outra, portanto, a sua atuação permitiu equalizar esta outra fonte de variação, sendo, portanto, este professor controle de si mesmo.

Nesta etapa foram realizadas sessões de observação de comportamento dos professores e alunos em sala de aula para acompanhamento das atividades nas turmas experimentais e de controle. O método de observação, o catálogo de categorias comportamentais desenvolvidos e os resultados foram descritos (Schall e col.*, 1987).

\section{3. etapa: Aplicação da entrevista posterior.}

A entrevista posterior foi aplicada 6 meses após a $2 .^{2}$ etapa (semestre seguinte), aos mesmos escolares entrevistados na $1 .^{a}$ etapa (Grupo I), totalizando 70 alunos, sendo 9 a menos do que naquela fase, devido à evasão escolar (Tabela 1 - Grupo I).

Nessa etapa foram repetidas as questões da entrevista anterior relativas ao conhecimento do caramujo transmissor e sobre a esquistossomose, e foram incluídas outras sobre avaliação geral da história ou folheto. Outro subgrupo da amostra, quantitativamente semelhante ao anterior (Tabela 1 - Grupo II), totalizando 72 alunos, foi selecionado aleatoriamente e submetido apenas à entrevista posterior, utilizando-se o questionário completo e as demais questões de avaliação do material. Como previsto pelo planejamento experimental (Modelo de Solomon ${ }^{25}$ - Tabela 2) os dados dessa amostra foram comparados aos dados da amostra entrevistada anteriormente a fim de verificar se a entrevista anterior poderia ter funcionado como variável interveniente no processo de aprendizagem. Esta amostra (Grupo II) funcionou como controle da amostra entrevistada "antes e depois".

\section{Metodologia de Análise}

Os dados relativos às entrevistas, exercícios, redaçōes, outras atividades relacionadas aos textos utilizados, e derivados de observação

Trabatho realizado por V. T. Schall; P. Jurberg; F. G. Cavalcante; S. Bagno; E. M. Almeida; C. Casz, intitulado "A observação de comportamento como auxílio à avaliação de um programa de educação sanitária em implantação". Dados inéditos. 
de comportamento de professores e alunos, foram sumarizados em tabelas e gráficos. O tratamento estatístico envolveu a prova de McNemar $\left(\right.$ Siegel $\left.^{43}, 1977\right)$ para a significância de mudanças, aplicável a planejamentos do tipo "antes e depois", em que o indivíduo é utilizado como seu próprio controle. Esta prova foi aplicada às questões da entrevista, da amostra submetida à entrevista anterior e posterior para medir a significância das mudanças de conhecimento provocadas pelo material testado.

A comparação estatística dos dados entre a amostra 1 e 2 foi avaliada pelo teste de $\chi^{2}$ (qui-quadrado) para 2 grupos independentes (Tabela de Contigência).

As cartas e redações, feitas pelos alunos após a segunda etapa, foram analisadas segundo Lefrève ${ }^{22}(1980)$ através de critérios tipológicos descritivos.

\section{RESULTADOS}

\section{Dados Gerais da Amostra}

Em geral, as crianças entrevistadas pertenciam a famílias de nível socioeconômico baixo, constatado pelas profissões dos pais, dos quais $61,7 \%$ se distribuíam entre operários, comerciários e serventes, outros $10,3 \%$, em biscates diversos, não estando disponíveis os dados de $28,0 \%$ dos pais. Quanto a profissão das mães, $59,8 \%$ eram domésticas e o restante subdividia-se entre comerciárias, operárias e auxiliares de enfermagem, cabeleireiras, etc. O levantamento sobre número de filhos, por família, revelou que $63,3 \%$ tem de 1 a 4 filhos, $31,6 \%$ de 5 a 8 e $5,1 \%$ de 9 a 12 .

\section{Análise das Entrevistas}

Foram analisadas no presente trabalho apenas as questões de entrevista diretamente relacionadas ao conhecimento sobre a esquistossomose. Uma destas questões investiga sobre o hábito de banho em ambientes naturais. A análise das respostas do Grupo I, a esta questão (I), entre a entrevista anterior e posterior revelou mudança significativa de opiniāo nas turmas experimentais e de controle (Teste de McNemar - Tabela 3). Constatou-se um grande número de escolares (41\%-turmas experimentais e $57 \%$-turmas controle) que antes respondeu sim, e passou a responder não após a aplicação do material instrucional. Portanto, na entrevista posterior, verificou-se que mais de $80 \%$ dos alunos diziam não tomar banho em lagoas ou rios (Tabela 4), não se observando diferença significativa entre as respostas dos Grupos I e II, tanto nas turmas experimentais quanto nas de controle teste qui-quadrado - Tabela 4).

A investigação dos motivos para banhar-se ou não em ambientes naturais permitiu verificar que entre os alunos que responderam sim, a maioria (acima de $50 \%$ ) o fazia por motivos de lazer ("para refrescar quando está calor". ., etc.), outros (cerca de 17\%) por motivos sociais (convite de amigos), ou por necessidade (acima de $15 \%$ ), estes justificando a ausência de banheiro ou água encanada em casa. Os motivos dados para as respostas negativas (não banhar-se em ambiente natural Tabela 5), referem-se a proibição (dos pais ou responsáveis); consciência do perigo quanto a poluição, sujeira ou transmissão de doenças, (que aumentou no grupo I, após a aplicação do material instrucional) e justificativas passi-

TABELA 3

Comparação das respostas do Grupo I, entre a entrevista anterior e posterior

\begin{tabular}{lccccccccccc}
\hline Condição & $\begin{array}{c}\text { Questões } \\
\text { Respostas }\end{array}$ & GE & & GC & GE & & GC & GE & GC & GE & GC \\
& & & & & & & & & & & \\
\hline Com mudança & Sim-Não & 20 & 12 & 1 & 2 & 3 & 1 & 1 & 1 \\
(Antes-Depois) & Não-Sim & 2 & 1 & 16 & 5 & 12 & 11 & 18 & 3 \\
Sem mudança & Sim & 5 & 4 & 24 & 10 & 31 & 8 & 7 & 3 \\
(Antes-Depois) & Não & 22 & 4 & 8 & 4 & 3 & 1 & 23 & 14 \\
\hline & Total & 49 & 21 & 49 & 21 & 49 & 21 & 49 & 21 \\
& McNemar & $13,13 * *$ & $7,69 *$ & $11,52 *$ & - & $4,57 *$ & $6,75 *$ & $13,47 * *$ & - \\
\hline
\end{tabular}

Obs.: Questões I (se toma banho em ambiente natural); II (se já conhece o caramujo); III (se o caramujo causa algum mal) e IV (se sabe o que é xistosomose).

$* \mathrm{p}<0,05 ; * * \mathrm{p}<0,01 ; * * * \mathrm{p}<0,001$.

GE: Grupo Experimental

GC: Grupo Controle.

-: Valores numericamente insuficientes para uso da prova de McNenar. 
TABELA 4

Comparação das respostas entre os Grupos I (antes e depois) e Grupo II (depois) na entrevista posterior

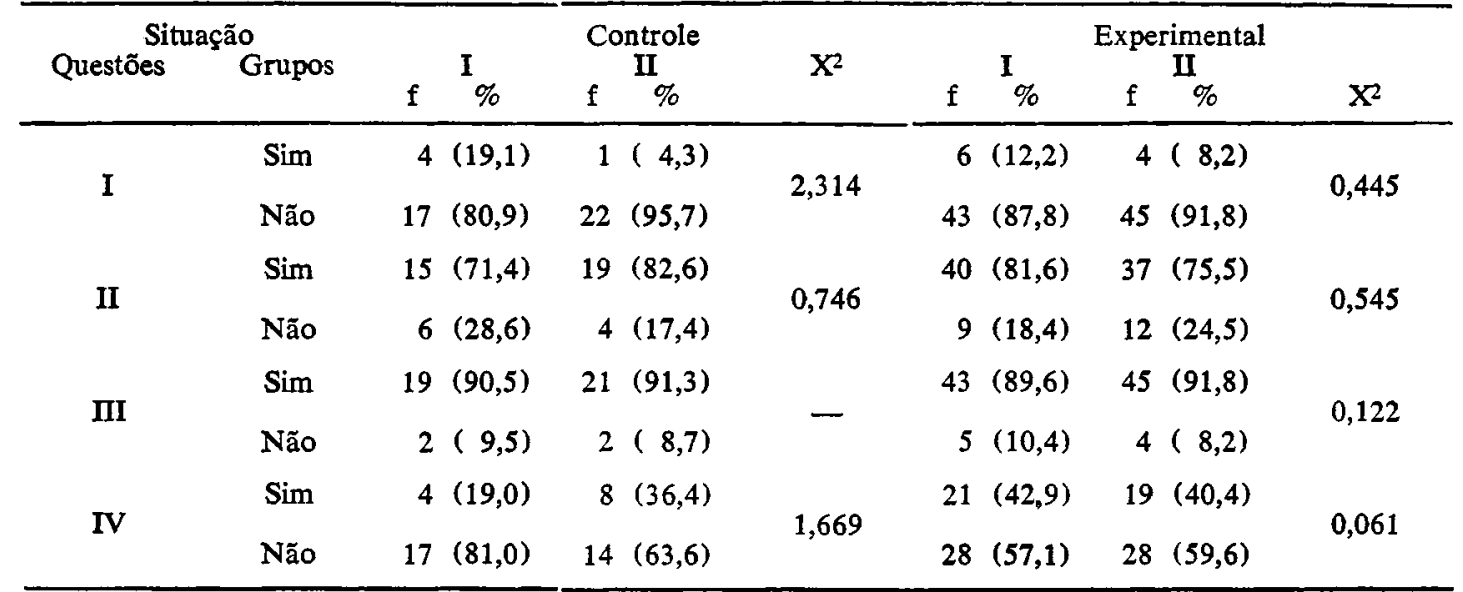

Obs.: Questões I (se toma banho em ambiente natural); II (se já conhece o caramujo); III (se o caramujo causa algum mal) e IV (se sabe o que é xistosomose). ${ }^{*} \mathrm{p}<0,05$.

TABELA 5

Distribuição das respostas dos alunos sobre motivos que os levam a não banhar-se em ambientes naturais

\begin{tabular}{|c|c|c|c|c|c|c|}
\hline \multirow{2}{*}{ Motivos } & \multicolumn{2}{|c|}{ EA } & \multicolumn{2}{|c|}{ EP } & \multicolumn{2}{|c|}{ EP' } \\
\hline & f & $\%$ & f & $\%$ & $\mathbf{f}$ & $\%$ \\
\hline 1. Por proibição dos pais ou & $\begin{array}{r}9 \\
15\end{array}$ & $\begin{array}{l}17,3 \\
288\end{array}$ & $\begin{array}{l}14 \\
42\end{array}$ & $\begin{array}{l}17,3 \\
519\end{array}$ & 12 & $\begin{array}{l}17,9 \\
478\end{array}$ \\
\hline $\begin{array}{l}\text { tumado/Passiva } \\
\text { 4. Sem justificativa }\end{array}$ & $\begin{array}{r}27 \\
1\end{array}$ & $\begin{array}{r}51,9 \\
1,9\end{array}$ & $\begin{array}{r}24 \\
1\end{array}$ & $\begin{array}{r}29,6 \\
1,2\end{array}$ & $\begin{array}{r}21 \\
2\end{array}$ & $\begin{array}{r}31,3 \\
3,0\end{array}$ \\
\hline Total & 52 & 100,0 & 81 & 100,0 & 67 & 100,0 \\
\hline
\end{tabular}

$X^{2}\left(E P \times E P^{\prime}\right.$ entre itens 1,2 e 3$)=0,156 ; g .1 .=2 ; p>0,05$.

$\mathrm{EA}=$ Entrevista Anterior (Grupo I).

EP = Entrevista Posterior (Grupo I - Entrevistado anterior e posteriormente).

EP' = Entrevista Posterior (Grupo II - Entrevistado apenas posteriormente).

vas como "não gosta", "não tem costume", "não existe local apropriado próximo de casa", motivos esses que são menos referidos na entrevista posterior em relação à entrevista anterior (Tabela 5).

Quanto às questōes sobre o reconhecimento do caramujo exibido ao vivo a cada aluno, e se o mesmo poderia causar algum mal, verificou-se, na entrevista anterior, que $51,0 \%$ e $57,1 \%$ dos alunos das turmas experimentais e controles respectivamente, afirmavam conhecer o animal e $69,4 \%$ (experimental) e $42,8 \%$ (controle) achavam que causaria algum mal. Já na entrevista posterior, $81,6 \%$ (experimental) e $71,4 \%$ (controle) da amostra reconhecia o animal e $87,7 \%$ (experimental) e $95,0 \%$ (controle) afirmava que 0 mesmo causava al- gum mal. Não se observou, para as duas questões, diferenças significativas entre os grupos I e II*, tanto nas turmas de controle e experimentais (teste de qui-quadrado, Tabela 4). A mudança de respostas, entre a entrevista anterior e posterior, foi significativa para a questão II (teste de McNemar - Tabela 5) nas turmas experimentais, sendo as respostas insuficientes para tratamento estatístico nas turmas de controle. Para a questão III, tal mudança foi significativa tanto para as experimentais quanto controles (Tabela 3).

Dos alunos que responderam já conhecerem - caramujo, na entrevista anterior, $68 \%$ apontou locais que não correspondem ao "habitat" do animal, como "perto de casa" (36\%) e "ambientes terrestres" (32\%). Já na entre-

* Grupo I (alunos sorteados aleatoriamente e submetidos a entrevista anterior e posterior).

Grupo II (alunos sorteados aleatoriamente, quantitativa e qualitativamente equivalentes aos do Grupo I, submetidos apenas à entrevista posterior). 
TABELA 6

Distribuição das alternativas dadas pelos alunos quanto ao local onde já haviam visto o caramujo

\begin{tabular}{|c|c|c|c|c|c|c|}
\hline \multirow{2}{*}{ Local } & \multicolumn{2}{|c|}{ EA } & \multicolumn{2}{|c|}{ EP } & \multicolumn{2}{|c|}{ EP' } \\
\hline & $\mathbf{f}$ & $\%$ & $\mathbf{f}$ & $\%$ & f & $\%$ \\
\hline $\begin{array}{l}\text { Perto da casa } \\
\text { Ambientes aquáticos } \\
\text { Ambientes terrestres } \\
\text { Livro } \\
\text { Escola } \\
\text { Não consta/Não viu }\end{array}$ & $\begin{array}{r}19 \\
13 \\
17 \\
4 \\
4 \\
-\end{array}$ & $\begin{array}{r}35,8 \\
24,5 \\
32,1 \\
7,5 \\
-\end{array}$ & $\begin{array}{r}9 \\
51 \\
11 \\
6 \\
3\end{array}$ & $\begin{array}{r}11,3 \\
63,8 \\
13,8 \\
\overline{7,5} \\
3,8\end{array}$ & $\begin{array}{r}7 \\
41 \\
12 \\
1 \\
12 \\
6\end{array}$ & $\begin{array}{r}8,9 \\
51,9 \\
15,2 \\
1,3 \\
15,2 \\
7,6\end{array}$ \\
\hline Total & 53 & 100,0 & 80 & 100,0 & 79 & 100,0 \\
\hline
\end{tabular}

Obs.: $\mathrm{EA}=$ Entrevista Anterior (Grupo I)

$\mathrm{EP}=$ Entrevista Posterior (Grupo I)

$\mathrm{EP}^{\prime}=$ Entrevista Posterior (Grupo II)

vista posterior, o local mais citado foi relativo a "ambientes aquáticos", sendo 64\% (Grupo I) e $52 \%$ (Grupo II — Tabela 6).

Quanto à questão III, observou-se que grande parte dos alunos $(54,1 \%)$, na entrevista anterior, não sabia que tipo de mal poderia causar o caramujo, $9,5 \%$ o associavam a transmissão de vermes e/ou micróbios e $33,8 \%$ a doenças incorretas e apenas $2,7 \%$ a transmissão de esquistossomose (Tabela 7). $\mathrm{Na}$ entrevista posterior, tanto para o Grupo I quanto o II, ocorreu mudança considerável nas respostas, $73,5 \%$ dos alunos passaram a associar o animal à transmissão de doenças, e destas, $22,4 \%$ à esquistossomose (Tabela 7).

Ao se investigar o conhecimento que os alunos tinham da esquistossomose, apenas $16 \%$ (turmas experimentais) e 18\% (turmas controles) responderam afirmativamente, na entrevista anterior. Analisando-se a mudança de respostas entre a entrevista anterior e posterior (Grupo I), verificou-se mudança significativa nas turmas experimentais (teste de McNemar, Tabela 3), em que 36\% que antes responderam não saber, passaram a fazê-lo. Já nas turmas de controle, registrou-se que apenas $14,3 \%$ dos alunos mudaram de opinião, e as respostas foram numericamente insuficientes para tratamento estatístico.

Analisando-se as alternativas dadas pelos alunos à palavra "xistosomose", verificou-se na entrevista anterior que $62,5 \%$ referiram-se a uma doença, sem especificar sintomas ou relacionando sintomas incorretos, o que na entrevista posterior decresce para $35,5 \%$ no Grupo I e $47,6 \%$ no Grupo II (Tabela 8). Quanto à identificação da doença com sintomas corretos, nāo se registrou tal alternativa na entrevista anterior, entretanto, após a aplicação do material, verificou-se $45,2 \%$ para o Grupo I e $16,7 \%$ para o Grupo II nesta categoria (T'abela 8).

Ao final da entrevista posterior, foi solicitado aos alunos um relato sobre o que haviam aprendido sobre a história (experimental) e o folheto (controle). Estes relatos foram avaliados considerando-se os seguintes níveis: Nível I: Mais de $80 \%$ do conteúdo transmitido, quando se mencionava pelo menos cinco itens dentre os seis referidos a seguir: 1) sintomas

TABELA 7

Distribuição das alternativas dadas pelos alunos sobre o que causaria o caramujo

\begin{tabular}{lrrrrrr}
\hline Alternativas & \multicolumn{2}{c}{ EA } & \multicolumn{2}{c}{ EP } & \multicolumn{2}{c}{ EP' } \\
& f & $\%$ & f & $\%$ & f & $\%$ \\
\hline $\begin{array}{l}\text { Não lembra/Não sabe/Nenhuma } \\
\quad \text { sugestão/Não consta }\end{array}$ & 40 & 54,1 & 13 & 26,5 & 19 & 24,7 \\
$\begin{array}{l}\text { Transmissão de vermes e/ou } \\
\quad \text { micróbios }\end{array}$ & 7 & 9,5 & 4 & 8,2 & 8 & 10,4 \\
$\begin{array}{l}\text { Doenças incorretas } \\
\text { "Xistosomose" }\end{array}$ & 25 & 33,8 & 21 & 42,9 & 33 & 42,9 \\
\hline Total & 2 & 2,7 & 11 & 22,4 & 17 & 22,1 \\
\hline
\end{tabular}

Obs.: $\quad \overline{E A}=$ Entrevista Anterior (Grupo I)

$\mathbf{E P}=$ Entrevista Posterior (Grupo I)

$\mathrm{EP}^{\prime}=$ Entrevista Posterior (Grupo II) 
TABELA 8

Distribuição das alternativas dadas pelos alunos para a palavra "xistosomose"

\begin{tabular}{|c|c|c|c|c|c|c|}
\hline \multirow{2}{*}{ Alternativas } & \multicolumn{2}{|c|}{ EA } & \multicolumn{2}{|c|}{ EP } & \multicolumn{2}{|c|}{$\mathrm{EP}$} \\
\hline & $f$ & $\%$ & $\mathbf{f}$ & $\%$ & f & $\%$ \\
\hline 1. Doença (não especificou) & 15 & 62,5 & 11 & 35,5 & 20 & 47,6 \\
\hline bactéria & 3 & 12,5 & 2 & 6,5 & 6 & 14,3 \\
\hline 3. Esqueceu & 5 & 20,8 & - & - & - & 2 \\
\hline 4. Remédio & 1 & 4,2 & - & - & - & - \\
\hline 5. Doença com sintoma de & + & & 14 & & & \\
\hline 6. Caramujo & - & 二 & 14 & $\underline{45,2}$ & $\begin{array}{l}7 \\
1\end{array}$ & $\begin{array}{r}16,7 \\
2,4\end{array}$ \\
\hline $\begin{array}{l}\text { 7. Parasito (relacionado a } \\
\text { "xistosomose") }\end{array}$ & - & - & 4 & 12,9 & 8 & 19.0 \\
\hline Total & 24 & 100,0 & 31 & 100,0 & 42 & 100,0 \\
\hline
\end{tabular}

$\mathrm{X}^{2}=\left(\mathrm{EP} \times \mathrm{EP}^{\prime} \operatorname{dos}\right.$ itens $1,2,5$ e 7$)=7,714 ; \mathrm{g} .1 .=3 ; \mathrm{p}>0,05$

Obs.: $\mathrm{EA}=$ Entrevista Anterior (Grupo I)

$\mathbf{E P}=$ Entrevista Posterior (Grupo I)

EP' $^{\prime}=$ Entrevista Posterior (Grupo II)

da doença; 2) hábitos que levam à contaminação de si e do meio; 3) características do caramujo transmissor; 4) tipo de exame para detectar a doença; 5) tratamento e 6) medidas sanitárias. Nível 2: Entre 55 a $75 \%$ do conteúdo acima mencionado (pelo menos quatro itens); Nível 3: $50 \%$ do conteúdo transmitido (três itens); Nível 4: Distorção do conteúdo, onde eram relacionados conteúdos incorretos e fantasias, como permanecer associando a doença ao feitiço, ou outras; Nível 5: Esquecimento do conteúdo.

Os resultados estão sumarizados na Tabela 9, para os Grupos I e II, turmas experimentais e de controle.

O somatório dos níveis 1,2 e 3 , que abrangem mais de $50 \%$ do conteúdo corretamente transmitido, revelou que para as turmas expe- rimentais corresponde a $79,2 \%$ (Grupo I) e $73,6 \%$ (Grupo II), portanto, a maioria mostrou boa retenção da história. Para as turmas de controle o somatório correspondeu a $43,8 \%$ (Grupo I) e $62,5 \%$ (Grupo II), o que representa pelo menos cerca de metade dos alunos com boa retenção. Verificou-se maiores percentuais de distorção e esquecimento do conteúdo nas turmas de controle em relação às experimentais (Tabela 9). Não se observou diferença significativa para os valores da amostra experimental, entre os Grupos I e II (teste qui-quadrado - Tabela 9).

\section{Análise das Redações Livres e Cartas, dos Exercícios e Redações com Auxílio de Figuras}

Através da classificação de Lefrève ${ }^{21}$ (1980) foram quantificados os textos com mensagem

TABELA 9

Avaliação do relato dos alunos quanto a história (experimental) ou folheto (controle) 6 meses após a sua aplicação

\begin{tabular}{|c|c|c|c|c|c|c|c|c|}
\hline \multirow{3}{*}{ Relatos } & \multicolumn{4}{|c|}{$\underset{\text { EP }}{\text { Grupo I }}$} & \multicolumn{4}{|c|}{$\underset{\text { EP' }}{\text { Grupo II }}$} \\
\hline & \multicolumn{2}{|c|}{ GC } & \multicolumn{2}{|c|}{ GE } & \multicolumn{2}{|c|}{ GC } & \multicolumn{2}{|c|}{ GE } \\
\hline & $f$ & $\%$ & $\mathbf{f}$ & $\%$ & $\mathbf{f}$ & $\%$ & $f$ & $\%$ \\
\hline $\begin{array}{ll}\text { Nivel } & 1 \\
\text { Nivel } & 2 \\
\text { Nível } & 3 \\
\text { Nível } & 4 \\
\text { Nível } & 5\end{array}$ & $\begin{array}{l}2 \\
5 \\
2 \\
7\end{array}$ & $\begin{array}{l}12,5 \\
31,2 \\
12,5 \\
43,7\end{array}$ & $\begin{array}{r}17 \\
8 \\
13 \\
5 \\
5\end{array}$ & $\begin{array}{l}35,4 \\
16,7 \\
27,1 \\
10,4 \\
10,4\end{array}$ & $\begin{array}{l}2 \\
6 \\
7 \\
5 \\
4\end{array}$ & $\begin{array}{r}8,3 \\
25,0 \\
29,2 \\
20,8 \\
16,7\end{array}$ & $\begin{array}{r}16 \\
13 \\
10 \\
7 \\
7\end{array}$ & $\begin{array}{l}30,2 \\
24,5 \\
18,9 \\
13,2 \\
13,2\end{array}$ \\
\hline Total & 16 & 100,0 & 48 & 100,0 & 24 & 100,0 & 53 & 100,0 \\
\hline
\end{tabular}

GE: $\mathrm{X}^{2}$ (Grupo I $\times$ Grupo II para todos os níveis) $=2,024 ; \mathrm{g} .1 .=4 ; \mathrm{p}>0,05$

Obs.: $\mathrm{GE}=$ Grupo Experimental

$G C=$ Grupo Controle

$\mathrm{EP}=$ Entrevista Posterior (Grupo I)

EP' = Entrevista Posterior (Grupo II) 
negativa (onde se apontam os comportamentos que devem ser evitados); com mensagem mista (que relacionam os comportamentos a serem evitados e as alternativas corretas, do tipo "não faça isso, faça aquilo"); e com mensagem positiva (apenas os comportamentos corretos são apontados). Os resultados mostraram que $70,9 \%$ dos textos das turmas experimentais e $48,8 \%$ das turmas de controle emitem mensagens negativas (o que deve ser evitado), tais como: "não tomar banho em rio contaminado, não defecar a céu aberto, ..."). Para as mensagens de conteúdo misto, foram encontradas $25,5 \%$ (experimental) e $43,9 \%$ (controles) (Fig. 3), e para as de conteúdo positivo, 7,3\% (controles) e $3,6 \%$ (experimentais). Verificou-se também que, no total, $57,1 \%$ das mensa. gens são de cunho didático e, dentre estas, $71 \%$ provêm das quintas séries e $29,0 \%$ da terceira série. Tal atividade não foi realizada nas $4 .^{2}$ séries. Pode-se concluir, portanto, que os conceitos de prevenção e ações corretas ficaram contrabalançadas no controle (folheto), e na experimental (história) houve mais ênfase na prevenção.

Analisando-se os exercícios realizados após a aplicação da história ou folheto, verificou-se que, para as turmas de controle, o que chamou mais atenção quanto à esquistossomose foi saber que na fase mais grave desta, o doente tem o baço e fígado aumentados, podendo apresentar "barriga d'água" $(28,9 \%)$ e que, os caramujos que parecem inofensivos podem ser transmissores da doença $(31,1 \%)$, respostas estas que totalizaram $60 \%$ das alternativas escolhidas pelos alunos.

Nas turmas experimentais, o que mais chamou atenção foi a imagem do gato que tem higiene $(47,9 \%)$, como, também, descobrir que o feitiço não era real, que o problema estava "nos bichinhos que ao sair dos caramujos causavam doença nas pessoas" $(35,4 \%)$. Estas alternativas totalizaram $83,3 \%$ das respostas dos alunos. Ainda nessas turmas foi solicitado aos alunos sugestões para ajudar o menino da história na luta contra a doença. As idéias sugeridas pelos alunos foram "botar uma placa no rio onde ele se banha", "faria o mesmo que Maneco fez", "avisaria a delegacia para pôr um guarda tomando conta da lagoa e pediria ajuda para fazer uma piscina de água corrente", "levaria o caramujo na casa das pessoas e explicaria o mal que faz", "montaria

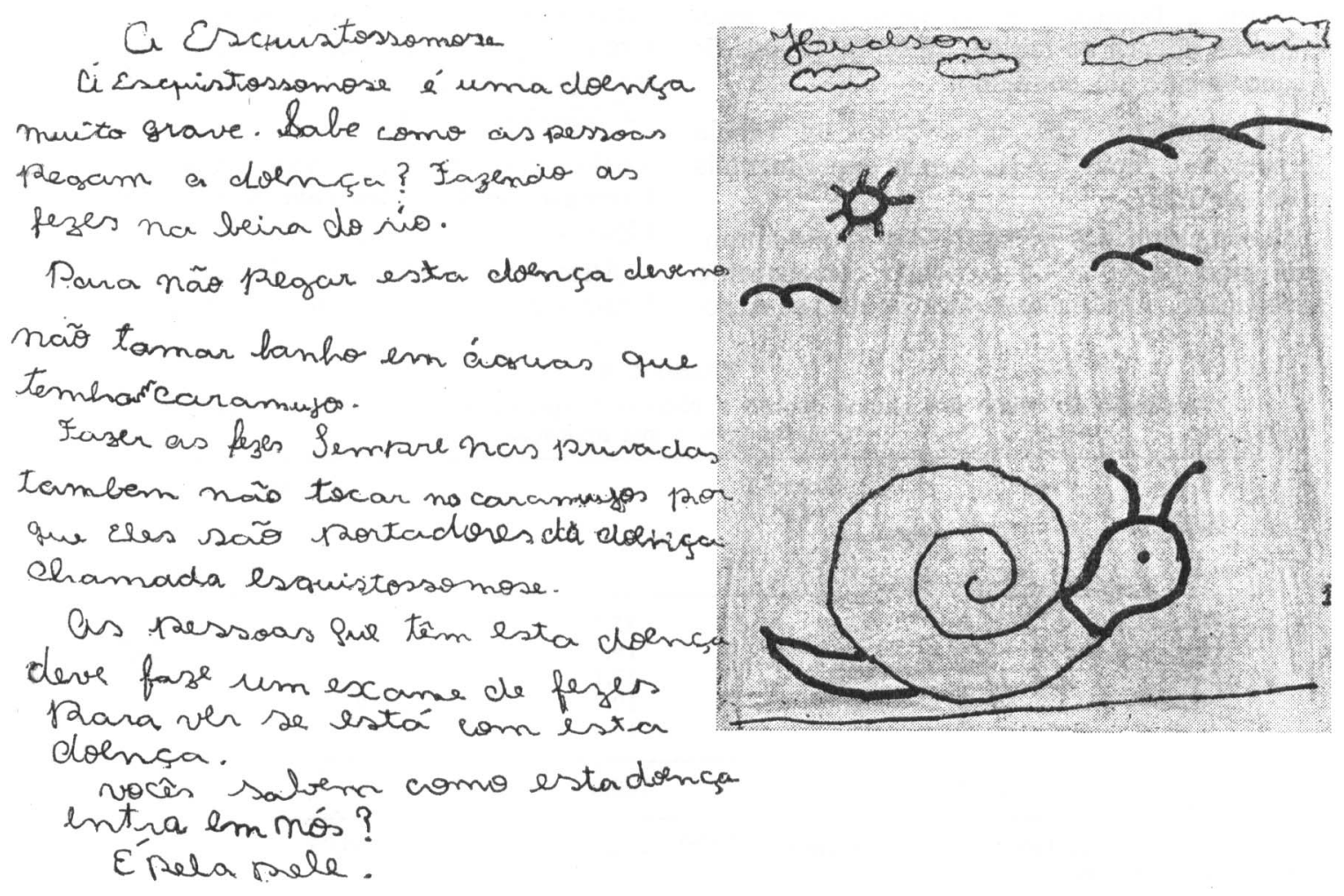

Fig. 3 - Redação de um estudante de $3 .{ }^{a}$ série do primeiro grau sobre a esquistossomose, classificada como sendo de "conteúdo misto". 
uma escola onde mostrem os bichos", "conversaria com as pessoas que entram na lagoa", "não lavaria roupas em águas paradas", "pediria a todos que ajudassem a acabar com essa doença". As mensagens transmitidas pelos alunos após lerem a história foram do tipo: "não devemos tomar banho em águas paradas e lugares desconhecidos", "eu não conhecia e agradeço por vocês me explicarem - às vezes eu posso estar com essa doença e não saber", "devemos fazer fossa em casa", "não fazer fezes em rios e lagoas", "faça como o gato", "todos devem ser iguais ao Maneco se estiverem com a doença", "não lavar roupas e nem tomar banho em rios e lagoas".

Nas turmas de controle foi investigado sobre o que os alunos achavam quanto ao que podia ser feito para prevenir a doença. As respostas obtidas foram: "não ter contato, tomar banho, lavar roupa, etc..., em água que possa estar contaminada" (41,2\%), "evitar poluir o meio com fezes" $(15,3 \%)$, "beber só água limpa (filtrada ou fervida)" $(8,2 \%)$, "ter hábitos higiênicos" $(7,1 \%)$, "só tomar banho em águas limpas ou correntes" $(5,9 \%)$, "ir ao posto de saúde" $(3,5 \%) ; 18,7 \%$ dos alunos não responderam.
Foi solicitado às turmas experimentais das escolas JSA e MM, recontarem a história em uma folha de papel ofício onde foram impressas reduzidas as 9 ilustrações do texto " $O$ Feitiço da Lagoa". Adjacente a cada ilustração havia espaço para os alunos escreverem o que haviam memorizado do texto. Estas redações com auxílio de figuras foram analisadas quanto ao conteúdo, avaliadas em três níveis (1 boa compreensão; 2 - regular e 3 - sem compreensão) e quanto à linguagem, avaliada pela escrita, com cópia do texto ou por versão própria. Tal análise mostrou que, no total, $60,0 \%$ dos alunos tiveram compreensão boa ou regular e $40,0 \%$ não foram capazes de recontar adequadamente a história, enquanto que $67,7 \%$ escreveram com versão própria e $32,3 \%$ copiaram o texto. Entretanto, observou-se uma variabilidade de resultados (Tabela 10) entre as turmas, como, entre a $3 \mathrm{~A}$ e 4B da JSA (Tabela 10), em que, na primeira série, $\mathbf{7 8 , 3} \%$ dos alunos tiveram compreensão boa ou regular e $91,4 \%$ escreveram com versão própria, já na segunda apenas $55,0 \%$ demonstraram compreensão e $55,0 \%$ escreveram com versão própria. Também na MM, observou-se tal discrepância, sendo o desempenho da turma 3B bem menos eficiente do que da turma $3 \mathrm{~A}$ e principalmente da 4A (Tabela 10).

TABELA 10

Análise das redações com auxílio de figuras sobre a história, feitas pelos alunos das escolas JSA e MM.

\begin{tabular}{|c|c|c|c|c|c|c|c|c|c|c|c|c|c|}
\hline \multirow{2}{*}{\multicolumn{2}{|c|}{$\begin{array}{l}\text { Escolas } \\
\text { Turmas }\end{array}$}} & \multicolumn{4}{|c|}{ JSA } & \multicolumn{6}{|c|}{ MM } & \multirow{2}{*}{\multicolumn{2}{|c|}{ Total }} \\
\hline & & $f$ & $\stackrel{3 \mathrm{~A}}{(\%)}$ & $f$ & $\begin{array}{l}\text { 4B } \\
(\%)\end{array}$ & f & $\begin{array}{l}3 \mathrm{~A} \\
(\%)\end{array}$ & f & $\begin{array}{l}3 \mathbf{B} \\
(\%)\end{array}$ & $\mathbf{f}$ & $\underset{(\%)}{4 A}$ & & \\
\hline Conteúdo & $\begin{array}{l}1 \\
2 \\
3\end{array}$ & $\begin{array}{r}10 \\
8 \\
5\end{array}$ & $\begin{array}{l}(43,5) \\
(34,8) \\
(21,7)\end{array}$ & $\begin{array}{l}6 \\
5 \\
9\end{array}$ & $\begin{array}{l}(30,0) \\
(25,0) \\
(45,0)\end{array}$ & $\begin{array}{r}10 \\
5 \\
13\end{array}$ & $\begin{array}{l}(35,7) \\
(17,9) \\
(46,4)\end{array}$ & $\begin{array}{r}5 \\
3 \\
12\end{array}$ & $\begin{array}{l}(25,0) \\
(15,0) \\
(60,0)\end{array}$ & $\begin{array}{l}5 \\
3 \\
1\end{array}$ & $\begin{array}{l}(55,6) \\
(33,3) \\
(11,1)\end{array}$ & $\begin{array}{l}36 \\
24 \\
40\end{array}$ & $\begin{array}{l}(36,0) \\
(24,0) \\
(40,0)\end{array}$ \\
\hline \multicolumn{2}{|l|}{ Subtotal } & 23 & $(100,0)$ & 20 & $(100,0)$ & 28 & $(100,0)$ & 20 & $(100,0)$ & 9 & $(100,0)$ & 100 & $(100,0)$ \\
\hline \multirow{2}{*}{\multicolumn{2}{|c|}{$\begin{array}{l}\text { Escrita com cópia } \\
\text { Sem cópia (versão } \\
\text { própria) }\end{array}$}} & 2 & $(8,6)$ & 9 & $(45,0)$ & 8 & $(28,6)$ & 12 & $(63,2)$ & 1 & $(11,1)$ & 32 & $(32,3)$ \\
\hline & & 21 & $(91,4)$ & 11 & $(55,0)$ & 20 & $(71,4)$ & 7 & $(36,8)$ & 8 & $(88,9)$ & 67 & $(67,7)$ \\
\hline \multicolumn{2}{|l|}{ Subtotal } & 23 & $(100,0)$ & 20 & $(100,0)$ & 28 & $(100,0)$ & 19 & $(100,0)$ & 9 & $(100,0)$ & 99 & $(100,0)$ \\
\hline
\end{tabular}

Obs.: Conteúdo - 1 - Boa compreensão; 2 - Regular; 3 - Sem compreensão.

\section{Analise do Comportamento de Professores e Alunos Observados Durante a Fase de Teste dos Materiais}

A utilização do material experimental (história) e de controle (folheto) foi acompanhada pela equipe de pesquisadores através de observação do comportamento dos docentes e alunos durante as atividades em classe. A metodologia de observação adotada baseou-se em Hutt e Hutt ${ }^{18}$ (1974).
A observação teve por objetivos avaliar 0 desempenho do professor e interesse da turma, os quais poderiam funcionar como variáveis intervenientes no processo de teste e serem responsáveis pelos resultados independente de qual fosse o material. Além disso, tencionava-se verificar a motivação e envolvimento dos alunos em relação aos materiais e a maneira mais eficiente do professor explorá-los. Um observador registrava continuamente $0 \mathrm{com}$ - 
portamento do professor e dois outros registravam por intervalo de tempo o de alunos escolhidos aletoriamente na sala de aula.

A análise de todo o registro comportamental permitiu elaborar um católogo de categorias comportamentais detalhado para avaliar a eficiência do professor, a interação com os alunos e a participação e interesse destes - 0 que pode ser útil a outras pesquisas de testes de materiais instrucionais. O repertório comportamental dos alunos incluiu 31 categorias de conteúdo verbal emitido, subdivididos em: dúvidas; solicitaçōes; declarações sobre a atividade acadêmica ou extra acadêmica; quantificação dos períodos de conversa sem conteúdos registrados; contato, e outras. Inclui também outras categorias referentes a movimentos e posturas como: olhar atento; olhar disperso; atividade motora, dirigida, ou paralela, ou dispersiva. O comportamento do professor foi descrito em 44 categorias de conteúdo verbal subdivididos em: explicar; orientar; motivar; advertir e questões alheias a atividade acadêmica. Também foi quantificada a explanação verbal total do professor, os recursos didáticos utilizados, o comportamento dispersivo e a intervenção verbal do observador, o que, no conjunto, permitiu avaliar a eficiência do professor. Todas as categorias foram definidas operacionalmente $\mathrm{e}$ as de conteúdo verbal exemplificadas. A descrição completa do catálogo se encontra em Schall e col. ${ }^{41}$ (1985).

Algumas das categorias de conteúdo verbal se basearam em descrição de Marturano ${ }^{24}$ (1984). Como afirma essa autora, é de grande importância a influência do professor sobre o aluno nas séries iniciais de escolarização, favorecendo ou não a sua aprendizagem. A quantificação e a análise estatística das categorias de cada professor em paralelo à de sua respectiva turma, denotou a importância da boa apresentação e exploração do material, o que foi proporcional à aprendizagem na maioria dos casos.

Como citado no item $\mathrm{b}$ deste artigo, o professor da turma 3A (escola JSA) tendo sido o mais eficiente entre 8 estudados, resultou na turma de maior percentual de conteúdo aprendido. Entretanto, sendo o professor da turma 4B, o menos eficiente dos 8 observados, o nível de aprendizagem de sua turma, avaliada 6 meses depois, foi superior ao das turmas testadas com o material de controle (folheto), o que ressalta a qualidade do material experi- mental (história) de motivar para o conhecimento, apesar, até certo ponto, da aptidão do professor.

\section{Reestruturação do Material e Proposta Educativa mais Ampla}

Algumas das atividades realizadas permitiram avaliar as partes da história que foram bem memorizadas e aquelas que não eram imprescindíveis à compreensão. Como o texto era bastante longo, sofreu um corte seletivo tornando o conteúdo mais objetivo e adequado à faixa etária a que se destina. Resta ainda testar ilustrações diferentes ou até aproveitar ilustraçōes das próprias crianças para compor - livreto. Foi desenvolvido também um guia de leitura para o professor, contendo sugestões de como melhor aproveitar o texto e realizar atividades posteriores como dramatizaçōes, redações, excursões de campo e replicação de experiências científicas, o que auxilia na memorização sobre a doença.

Do trabalho surgiram várias propostas, algumas das quais pretendemos testar, com a realização de uma "semana da saúde" aproveitando a experiência bem sucedida das "Feiras de Ciências". Nesta semana, professores e alunos se reuniriam para expor materiais explicativos, desenvolver atividades de demonstração dos problemas de saúde da região à comunidade, convidar conferencistas, realizar dramatizações, replicações de experiências científicas relacionadas aos temas, no sentido de divulgar o conhecimento às famílias e sedimentá-lo nas crianças.

Concursos de redações ou outros poderiam ampliar a motivação. Livros como os de Bamberger $^{4}$ (1977), Rodari ${ }^{39}$ (1982), Cunha ${ }^{14}$ (1983), Milanesi ${ }^{27}$ (1983), Resende ${ }^{37}$ (1983) e Zilberman $^{45}$ (1981), dentre outros, sugerem atividades interessantes que poderiam ser adaptadas a área de saúde, tal como a realização de um juri simulado sobre uma doença, em que especialistas ou estudantes preparados tecem acusações e defesas em torno do assunto.

Outra sugestão que poderia ser de grande utilidade seria a criação de uma "ciranda de saúde" baseada no modelo das bibliotecas do tipo "Ciranda de Livros"* cujo sistema vem sendo altamente enriquecedor na área da literatura infantil. Sistema semelhante poderia ser desenvolvido como uma forma de se ler nas escolas um material básico sobre diversas

* Projeto desenvolvido pela Fundação Nacional do Livro Infantil e Juvenil (FNLIJ), pela Fundação Roberto Marinho e a Hoechst do Brasil. 
doenças. $O$ encarte plástico conteria exemplares de histórias sobre as doenças, modelos artificiais com características reais idênticas aos animais transmissores, cartões com desenho dos parasitas sob lente de aumento, manual para o professor com sugestões de metodologia, cartazes explicativos, reprodução ampliada de figuras do texto e retratos de pessoas doentes ressaltando os sintomas. Cada escola poderia contar com um ou dois desses encartes, os quais poderiam ser utilizados por todos os professores num sistema de rodízio. Adequações regionais podem ser feitas, haja vista que existem, como para a esquistossomose, outros textos disponíveis para aproveitamento como o aqui sugerido. Podemos citar como exemplo a revista em quadrinho "A festa agora é nossa"1 (1977); Schistosoma o verme do terror (Silva $\left.{ }^{42}, 1975\right)$, típica literatura de cordel e o "Almanaque da Xistose"2 (1985).

Este sistema poderia ser aplicado a outras doenças, como por exemplo, para a doença de Chagas, sobre a qual refere-se a história "O Vampiro da Noite" (Almeida ${ }^{3}, 1978$ ) destinada a crianças. Estes são exemplos que poderiam servir de estímulo a criação específica para outras doenças, o que tornaria mais sistemático, interessante e lúdico, o ensino sobre doenças parasitárias nas escolas de primeiro grau.

\section{DISCUSSÃO}

Verificou-se, através das entrevistas, que ocorreu mudança significativa de conhecimento quanto a aspectos da transmissão, sintomas e caracterização da esquistossomose. Entretanto, a mudança significativa verificada quanto à questão sobre a atitude de banhar-se em rios ou águas de outros ambientes naturais não pode ser interpretada como um indicador de mudança de hábito, mas apenas como um índice de aumento de consciência do risco que representam tais ambientes para a aquisição da doença. Seria simplista pensar que as crianças que antes diziam ter tal hábito, e 6 meses após a aprendizagem, passaram a dizer "não", realmente mudaram de atitude. Pode-se imaginar que a continuidade do processo educativo e a consolidação de tal conscientização poderá até conduzir a uma mudança de hábitos, o que, entretanto, não esteve ao alcance desta etapa do trabalho.

Quanto ao reconhecimento do molusco vetor da esquistossomose, verificou-se uma aprendizagem maior entre os alunos que viram um exemplar real do animal. Alunos que apenas viram desenhos do molusco vetor, continua- ram a associar a doença com qualquer espécie de caramujo ou "caracol", até mesmo terrestres ou marinhos, sem adquirir uma noção discriminada do tamanho e características morfológicas típicas da espécie vetora.

Essa evidência nos leva a discutir a eficiência do ensino através de esquemas e modelos desenhados que não transmitem aos alunos elementos de discriminação na aprendizagem, mas levam a generalização do conteúdo, decorrendo daí concepções errôneas do tipo: "qualquer molusco transmite doenças". Para a faixa etária estudada é de grande necessidade um ensino, o mais concreto possível, com uso de materiais que facilitem a discriminação. Isso alertou também quanto às características do parasito (miracídio e cercária) que, em todos os materiais educativos sobre esquistossomose, são representados em tamanhos muito maiores do que os reais, o que induz nas crianças noções incorretas, mesmo que verbalmente se chame atenção sobre tal deficiência dos desenhos. A aprendizagem visual exerce uma memorização muito marcante e quanto mais se aproximar da realidade, tanto melhor. Desenhar lentes de aumento em torno do desenho das formas jovens do parasito pode ser um recurso adequado, que melhora a noção de tamanho dos animais. Ao especialista pode parecer pouco provável que uma criança, observando um ambiente aquático, procure ali cercárias, que, pelos desenhos, imagina serem do tamanho de peixinhos, mas tal fato ocorre com frequiência.

Outro ponto observado refere-se às mensagens solicitadas aos alunos que aprenderam através da história (turmas experimentais) e aqueles que usaram os folhetos da SUCAM (turmas de controle), quanto às providências que tomariam em relação a doença. Verificou-se que as mensagens dos primeiros são mais criativas, envolvendo atitudes de comunicação e sociabilização como os exemplos citados no item $\mathrm{C}$ dos resultados. Já as mensagens das turmas de controle caracterizam-se por recomendações memorizadas do tipo "não fazer isso, fazer aquilo", expressas na própria linguagem do folheto. E necessário que tais cuidados estejam bem estabelecidos, entretanto, a dimensão social de ação que é motivada pela história é um avanço importante no sentido de mobilização de atitudes dos alunos.

Por outro lado, sendo o objetivo principal deste trabalho desenvolver um material educativo sobre uma doença, isto nos remete à questão da educação para a saúde, a qual, por sua vez, está vinculada à questão da educação 
escolar no Brasil. Reflete-se na educação para a saúde toda a problemática da educação, que, nas escolas públicas necessita ser repensada como um todo mediante a deteriorização progressiva que historicamente se processou, fruto da situação socioeconômica-política do país.

O quadro que atualmente encontramos está bem representado pela recente pesquisa Gallup* que mostra as altas taxas de abandono escolar no Brasil. Esta pesquisa revelou que "de cada 100 brasileiros que atingem a idade escolar, 74 ingressam na primeira série do primeiro grau (para 26 faltam escolas ou vagas disponíveis), apenas 12 chegam ao final do primeiro grau, 8 chegam à primeira série do segundo grau e destes apenas a metade conclui os 3 anos de duração do curso".

Quanto aos programas de educação para a saúde, os mais elaborados estão restritos a escolas secundárias alcançando assim uma pequena percentagem da população em idade escolar. Torna-se necessário e mesmo indispensável, desenvolver materiais e métodos que se destinem às primeiras séries do primeiro grau de forma a ampliar o alcance da educação para a saúde.

No primeiro grau, o programa de educação em saúde está inserido no currículo de Ciências das Secretarias de Educação. O trabalho de Carraher e col. ${ }^{5}$ (1985) com professores de primeiro grau, de escolas públicas em Recife, demonstrou que relativamente "pouco tempo por semana é efetivamente utilizado para o ensino de ciências (cerca de $2 \mathrm{~h} 30 \mathrm{~min}$. oficialmente, que são reduzidas por problemas do tipo: atraso ou falta do professor e atividades dispersivas destes)". Além disso, em nenhuma das escolas os alunos compravam os livros de ciências, não havia tarefa de observação científica, e apenas transmissão de informaçōes técnicas, crendo os profissionais que aprender é memorizar. Outro agravante é o fato de serem os programas de ensino feitos pelos próprios professores que apenas copiam os índices dos livros adotados. Os professores querem cumprir o programa ao invés de fazer um programa. Os AA. reforçam a necessidade de se alterar os programas "substituindo conteúdos a serem transmitidos" por "atividades a serem desenvolvidas". Tal mudança é difícil porque o professor depende dos textos adotados e, portanto, um projeto que vise melhorar o ensino de ciências e mais especificamente, da saúde, precisa oferecer textos alternativos e orientar os professores sobre a sua utilização, textos estes que devem ser pesquisados quanto à sua adequação e eficácia. E preciso levar em conta que, em geral, nas escolas públicas, as salas de aula estão sempre lotadas e os professores sobrecarregados de trabalho, motivo pelo qual os materiais devem ser simples, práticos e relacionados a questões locais, de tal forma que possam ser usados sem causar-lhes acréscimo de trabalho. O sucesso na implementação de um programa de educação depende de como os professores são treinados e do apoio que recebem na introdução do novo material.

Como exemplo, na implementação de programas de educação populacional, em lugares como Baltimore (EUA) e Filipinas, os materiais didáticos mais bem sucedidos mostram ser aqueles cuja preparação contou com a ajuda dos próprios professores (Populations $\mathrm{Re}$ ports $\left.{ }^{36}, 1982\right)$.

Tais programas devem estabelecer comunicação estreita com a comunidade onde a escola está inserida, trazendo-a para participar ativamente dos programas de saúde da comunidade, como recomenda Marcondes ${ }^{23}$ (1972).

A proposta contida no presente trabalho é uma semente que pode alcançar desenvolvimento, uma vez que busca soluções para vários problemas como: atingir maior contingente de crianças, sendo os materiais destinados às primeiras séries do primeiro grau, e distribuídos em encartes para uso coletivo nas escolas, desobrigando 0 aluno de adquiri-los, oferecer um manual de instrução ao professor que o estimula a desenvolver atividades usando a sua própria criatividade e sugerir ações integradas com a comunidade local.

\section{AGRADECIMENTOS}

A Maurício Carvalho de Vasconcellos e Brani Rozemberg pela colaboração na fase final do trabalho e a Ricardo Lourenço-de-Oliveira e Marli Maria Lima pela leitura crítica do texto. Às diretoras das escolas investigadas: professoras Maria Cristina Burgos Ribeiro, Maria Coeli S. M. Pontes e Luce Diegues, pela colaboração. Agradecem especialmente à professora Lygia Lyrio da Cunha cuja aptidão e criatividade acrescentaram muito a este trabalho.

* Revista "Veja", 9 de outubro de 1985. 
SCHALL, V. T. et al. [Health education for primary school students: evaluation of a didatic material for instruction and prevention on schistosomiasis]. Rev. Saúde públ., S. Paulo, 21:387-404, 1987.

ABSTRACT: Considering the importance of information about schistosomiasis for students 7-15 years old, age groups at risk of exposure to the disease and whose habits contribute to its spread, a brochure based on a literary text was elaborated and applied in schools situated within an isolated focus of the disease in Rio de Janeiro, Brazil. A method to make use of the material to be employed by the teachers was successful in the learning of concepts and primary care of schistosomiasis. The use of this method is proposed also in relation to other parasitic diseases to be applied in characteristically endemic areas.

UNITERMS: Health education, methods. School health. Schistosomiasis, prevention and control. Teaching materials.

\section{REFERENCLAS BIBLIOGRÄFICAS}

1. A festa agora é nossa. São Paulo, Abril S/A Cultural e Industrial Pfizer Química Ltda., 1977. [Quadrinhos utilizados no Programa Especial de Controle da Esquistossomose do Ministério da Saúde].

2. ALMANAQUE da Xistose. Salvador, Departamento de Medicina Preventiva. Faculdade de Medicina da UFBa, 1985. (Caderno de Educação n. ${ }^{\circ}$ 3).

3. ALMEIDA, L. M. O Vampiro da Noite. Belo Horizointe, Academia Mineira de Medicina. 1978. [folheto].

4. BAMBERGER, R. Como incentivar o hábito da leitura. Brasília, Cultrix, 1977.

5. CARRAHER, D. N.; CARRAHER, T. N.; SCHLIEMANN, A. I. Caminhos e descaminhos no ensino de ciências. Ciênc. e Cult., 37:889-96, 1985.

6. CASTRO-FILHO, J. \& SILVEIRA, A. C. As grandes endemias das crianças brasileiras. Rev. bras. Malar., 31:173-83, 1979.

7. CONCEIÇÃO, M. J. \& COURA JR., Indices de transmissão de esquistossomose mansoni em crianças menores de 10 anos, vivendo em área endêmica. Rev. Soc. bras. Med. trop., 12:105-7, 1978.

8. COSTA, D. Nota sobre a água como problema de educação sanitária em áreas de esquistos. somose. Rev. bras. Malar., 16:123-7, 1964.

9. COSTA, M. F. F. L.; KATZ, N.; DIAS, J. C. P. Reinfecção de pacientes em áreas endêmicas de esquistossomose mansoni após tratamento específico. IV - Observações em Belo Horizonte. Rev. Inst. Med. trop. S. Paulo, 22:97-155, 1980.

10. COTTA, E. \& ANDRADE, R. M. A esquistossomose mansoni em Belo Horizonte, MG (Brasil): situação antiga e atual do problema. Rev. bras. Malar., 19:161-4, 1967.

11. COURA, J. R.; CAMILLO-COURA, L.; KALACHE, A.; ARGENTO, C. A. Esquistossomose aguda autóctone de foco na cidade do Rio de Janeiro. Estudo de 22 casos. Rev. Soc. bras. Med. trop., 4:387-97, 1970.
12. COURA, J. R.; CONCEIÇÃO, M. J.; MENEZES, A. P.; SANTOS, M. L.; MENDONÇA, M. Z. G. Morbidade da esquistossomose mansoni no Brasil. II - Estudo em quatro áreas de campo nos Estados de Minas Gerais, Sergipe e Paraíba. Mem. Inst. Oswaldo Cruz, 78:1-11, 1983.

13. COUTINho, L. M. \& PIMONT, R. P. Educação em saúde e comunicação de massa numa experiência concreta no combate a esquistossomose. Tecnol. educ., 10(4):47-52, 1981.

14. CUNHA, M. A. A. Literatura infantil: teoria e prática. São Paulo, Ática, 1983.

15. EJEZIE, G. C. \& ADE-SERRANO, M. A. Schistosoma haematobium in Africa Community of Gadagry, Nigeria: a study on prevalence, intensity and morbity from infection among primary schoolchildren. Trop. geogr. Med., 33:175-80, 1981.

16. FAROOQ, Q. M. \& SAMAAN, S. A. The relative potential of different age-group in the transmission of schistosomiasis in Egypt-49 project area. Ann. trop. Med. Parasit., 61: 315-20, 1967.

17. GREEN, L. W. School health education. Ann. Rev. publ. Hlth, 3:321-8, 1982.

18. HUTT, S. J. \& HUTT, G. Observaçâo direta $e$ medida do comportamento. São Paulo, EPU/EDUSP, 1974.

19. KATZ, N.; ZICKER, F.; ROCHA, R. S.; OLIVEIRA, V. B. Reinfection of patients in schistosomiasis mansoni endemic areas after specific treatment. Rev. Inst. Med. trop. S. Paulo, 20:273-8, 1978.

20. KATZ, N.; ROCHA, R. S.; PEREIRA, J. P. Controle da esquistossomose em Péri-Péri (Minas Gerais) através de repetidos tratamentos clínicos e aplicações de moluscicida. Rev. Inst. Med. trop. S. Paulo, 22(Supl, 4): 203-11, 1980.

21. KNUTSON, A. L. Prestesting health education materials. Amer. J. publ. Hlth, 43:193-7, 1953. 
22. LEFEVRE, F. Análise de cartazes sobre esquistossomose elaborados por escolares. Rev. Saúde públ., S. Paulo, 14:396-403, 1980.

23. MARCONDES, R. S. Educação em saúde na escola. Rev. Saúde públ., S. Paulo, 6:89-96, 1972.

24. MARTURANO, E. M. Escolarização inicial: reflexões sobre a formação do professor. Arq. bras. Psicol., 36(2):11-125, 1984.

25. MATHESON, D. W.; BRUCE, R. L.; BEAUCHAMP, K. L. Introduction to experimental psychology. New York, Holt, Rinehart and Winston, 1970.

26. MENESES, A. P. \& COURA, J. R. Indice de transmissăo da esquistossomose na cidade de Riachuelo, Sergipe. Rev. Soc. bras. Med. trop., 13:21-4, 1979.

27. MILANESI, L. $O$ que é biblioteca. São Paulo. Brasiliense, 1983.

28. OLIVEIRA, J. C. A. Glossário de tecnologia educacional. Rio de Janeiro, Instituto de Tecnologia Educacional, 1979.

29. PAES, R.; MENEZES, A. B.; CAMARGO, S. Um novo foco de esquistossomose na Guanabara, Alto da Boa Vista. Rev. bras. Malar. 22:203-29, 1970 .

30. PAULINI, E.; DIAS, E. P.; FIUZA, H. Contribuição a epidemiologia da esquistossomose em Belo Horizonte, Rev. bras. Malar., 19: 571-606, 1967.

31. PELLON, A. B. \& TEIXEIRA, I. $O$ inquérito helmintológico escolar em cinco Estados das regiōes Leste, Sul e Centro-Oeste. Rio de Janeiro, Divisão de Organização Sanitária do Ministério da Saúde, 1953. [Mimeografado].

32. PEREIRA, H.; PELEGRINO, J.; COELHO, P. M. Z. $O$ que é esquistossomose? Belo Horizonte, Imprensa Universitária, s.d.

33. PERSIGAN, T. P.; FAROOQ, M.; HAIRSTON, N. G.; JAUREGUI, J. J.; GARCIA, E. G.; SANTOS, A. T.; BESA, A. A. Studies on Schistosoma japonicum infection in the Philippines. Bull. Wld Hlth Org., 18:345-455, 1958.
34. PESSOA, S. B. \& AMORIM, J. P. Contribuição para a história natural da esquistossomose mansônica no Nordeste brasileiro e sugestões para a sua profilaxia. Rev. bras. Malar., 9:5-18, 1957.

35. POLDERMAN, A. M. Intestinal schistomiasis north and east of Lake Tana, Ethiopia. Trop. geogr. Med., 26:170-7, 1974.

36. POPULATION REPORTS. Série M: Assuntos Especiais. (Johns Hopkins University) Baltimore, (6), 1982.

37. RESENDE, V. M. Literatura infantil \& juvenil: relatos de experiências na escola. Belo Horizonte, Ed. Comunicação, 1983.

38. REY, L. Contribuiçöes para o conhecimento da morfologia, biologia e ecologia dos planorbídeos brasileiros transmissores da esquistossomose. Rio de Janeiro, S.N.E.S., 1956.

39. RODARI, G. Gramática da fantasia. São Paulo, Summus Ed., 1982.

40. SCHALL, V. T. O feitiço da Lagoa. s.l., 1982. [Mimeografado].

41. SCHALL, V. T.; JURBERG, P.; WILLCOX, H. P. F.; CAVALCANTE, F. G.; BAGNO, S. Esquistossomose mansoni autoctone e outras parasitoses intestinais em escolares do Bairro Alto da Boa Vista da Cidade do Rio de Janeiro. Rev. Soc. bras. Med. trop., 18:169-74, 1985.

42. SILVA, D. M. Schistosoma, o verme do terror. "Estória dramática da luta do homem contra o verme e vice-versa. Quem vencerá?" Olinda, Editora Universitária, 1975.

43. SIEGEL, S. Estatistica não paramétrica: para as ciências do comportamento. São Paulo, McGraw-Hill do Brasil, 1977.

44. VINHA, C. A. A situação da esquistossomose no Estado do Rio Grande do Norte. Rev. bras. Malar., 20:3-37, 1968.

45. ZILBERMAN, R. A literatura infantil na escola. São Paulo, Global Ed., 1981.

Recebido para publicação em: 22/ 5/1986 Aprovado para publicação em: $12 / 11 / 1986$ 